Article

\title{
Roll Bonding Properties of Al/Cu Bimetallic Laminates Fabricated by the Roll Bonding Technique
}

\author{
Mohammad Heydari Vini ${ }^{1, *}$, Saeed Daneshmand ${ }^{2}$ and Mostafa Forooghi ${ }^{2}$ \\ 1 Department of Mechanical Engineering, Mobarakeh Branch, Islamic Azad University, Mobarakeh, \\ Isfahan 8631656451, Iran \\ 2 Department of Mechanical Engineering, Majlesi Branch, Islamic Azad University, Majlesi, \\ Isfahan 8159716778, Iran; S.daneshmand@iaumajlesi.ac.ir (S.D.); mostafa.forooghi58@gmail.com (M.F.) \\ * Correspondence: m.heydari@mau.ac.ir; Tel.: +98-(0)913-235-5319
}

Academic Editor: Manoj Gupta

Received: 1 May 2017; Accepted: 29 May 2017; Published: 8 June 2017

\begin{abstract}
Roll bonding (RB) of bimetal laminates is a solid phase method of bonding and has been widely used in the manufacturing of layered strips. This process is widely used for brazing sheet for automotive, aerospace, vessel, and electrical industries. In this study, 1-mm bimetallic aluminum 1050 and pure copper $(\mathrm{Al} / \mathrm{Cu})$ laminates were produced using the roll bonding $(\mathrm{RB})$ process. The RB process was carried out with thickness reduction ratios of $10 \%, 20 \%$, and $30 \%$, separately. Particular attention was focused on the bonding of the interface between $\mathrm{Al}$ and $\mathrm{Cu}$ layers. The optimization of thickness reduction ratios was obtained for the improvement of the bond strength of bimetallic laminates during the RB process. Also, the RB method was simulated using finite element simulation in ABAQUS software. Finite Element (FE) simulation was used to model the deformation of bimetallic laminates for various thickness reduction ratios, rolling temperatures, and tensile stresses. Particular attention was focused on the rolling pressure of $\mathrm{Al}$ and $\mathrm{Cu}$ layers in the simulation. The results show that the stress distribution in the bimetal $\mathrm{Al} / \mathrm{Cu}$ laminates is an asymmetrical distribution. Moreover, the bonding strength of samples was obtained using the peeling test. Also, the fracture surface of roll bonded samples around the interface of laminates after the tensile test was studied to investigate the bonding quality by scanning electron microscopy (SEM).
\end{abstract}

Keywords: roll bonding (RB); bond strength; bimetal laminates; peeling test; Finite Element Method (FEM)

\section{Introduction}

Today, there is a growing need for the use of bimetal laminates with special capabilities and characteristics, including high mechanical properties, corrosion resistance, light weight, good wear resistance, and thermal stability. Bimetallic $\mathrm{Al} / \mathrm{Cu}$ laminates have become increasingly popular for engineering applications since they usually possess several desirable properties such as excellent mechanical properties, corrosion resistance, and low density. They are employed in various fields such as the aerospace, automotive, vessel, and electrical industries [1-3]. Among the composite material technologies, Accumulative Roll Bonding (ARB) is an important technique used to produce laminates because the rolling pressure can create a mechanical bond between the metal such as $\mathrm{St} / \mathrm{Br}$ [4], $\mathrm{Cu} / \mathrm{Fe}$ [5], $\mathrm{Cu} / \mathrm{Ag}$ [6], $\mathrm{Al} / \mathrm{Zn}$ [7], $\mathrm{Al} / \mathrm{Ni}$ [8], $\mathrm{Al} / \mathrm{Fe}$ [9], Al/Mn [10], etc. In other studies, for aluminum alloys, two grades of these alloys were also used as starting materials such as AA1050/AA5083 [11]. Finally, the mechanical properties and microstructural evolution of these composites have been investigated. Different severe plastic deformation (SPD) techniques as special processes to produce ultra-fine grain (UFG) materials have been developed, such as accumulative roll bonding (ARB) $[11,12]$. Saito et al. proposed the ARB process for the first time [13]. During ARB, rolling is conducted on two 
layered sheets which have the exact same dimensions and have been stacked together. Many research studies have been carried out to investigate the effective parameters in the bonding process in order to understand the behavior of the bonding mechanism. It has been reported that the roll bonding of metals is affected by various factors such as rolling thickness reduction [11], bonding temperature [12], annealing treatment before and after the Roll Bonding (RB) process [13], welding time [14], rolling direction [14], metal purity [15], lattice structure [15], surface preparation [14], rolling speed [14], and the metal under investigation [15]. There have been many finite element method investigations conducted based on the rolling process. Dixit et al. [16] developed a new Finite Element Method (FEM) model of the cold flat rolling process. In his model, the effect of work hardening is highlighted. Shi et al. [17] observed a significant difference between the roll torques by the energy balance method. For plasticity problems, some friction models have been used to evaluate applied loads, material flows, and deformation, as reviewed by Schley [18]. For dynamic friction conditions, Tan developed a new dynamic friction model and successfully applied it to establish a solution to the point-strain compression [19]. Tadanobu et al. developed a finite element method simulation for the accumulative roll bonding process. He developed his simulation for three cycles of the ARB process and investigated the effect of plastic strain on the equivalent plastic strain of laminates. In this study, we report an investigation of the rolling of bimetallic $\mathrm{Al} / \mathrm{Cu}$ laminates. The rolling pressure under various thickness reduction ratios, tensile stresses, and rolling temperatures were quantitatively analyzed by the Finite Element Method (FEM). Also, the bond strength of $\mathrm{Al} / \mathrm{Cu}$ bimetallic laminates produced by the RB process with various thickness reduction ratios were reported by using the peeling test. Fracture surfaces of the tensile test specimens were observed by scanning electron microscopy (SEM). The observations were used to analyze the bond quality.

\section{Materials and Methods}

\subsection{Experimental Investigations}

The RB technique is used to fabricate bimetallic composites. RB-processed or one cycle ARB-processed samples were sheets of annealed pure $\mathrm{Al}$ and $\mathrm{Cu}$ with initial dimensions of $100 \times 30 \times 1 \mathrm{~mm}$. To produce a satisfactory mechanical bond by the RB technique, it is essential to remove contaminants from the surface of strips to be joined. These layers are composed of greases, oxides, adsorbed ions and dust particles. Then, $\mathrm{Al}$ and $\mathrm{Cu}$ strips were degreased in an acetone bath and scratch-brushed with a 90-mm diameter stainless steel circumferential brush with $0.35-\mathrm{mm}$ wire diameter and a speed of $2500 \mathrm{rpm}$ in order to remove the oxide layer on the surfaces of strips. One strip of $\mathrm{Al}$ and another of $\mathrm{Cu}$ were stacked together to achieve a thickness of $2 \mathrm{~mm}$. Proper alignment of the two strip surfaces prior to rolling is necessary. Figure 1 illustrates the SEM micrograph of the scratch-brushed surfaces of the aluminum strips before and after wire brushing and degreasing. According to Figure 1, wire brushing provides rough surfaces with a greater amount of surface asperities and introduces a localized shear deformation that breaks surface oxide films during the rolling process. Also, as can be seen in Figure 1, the surface layer is highly deformed in the wire brushing direction and some asperities and cracks are formed. According to Figure 2, the stacked strips were fastened by wires at both ends and were carefully handled to avoid renewed contamination. To prevent the formation of any thick surface oxides between layer strips, specimens were rolled as soon as the surface preparation was complete. Then, the specimens were roll-bonded with thickness reductions of $10 \%, 20 \%$, and $30 \%$ at $300{ }^{\circ} \mathrm{C}$, respectively. 


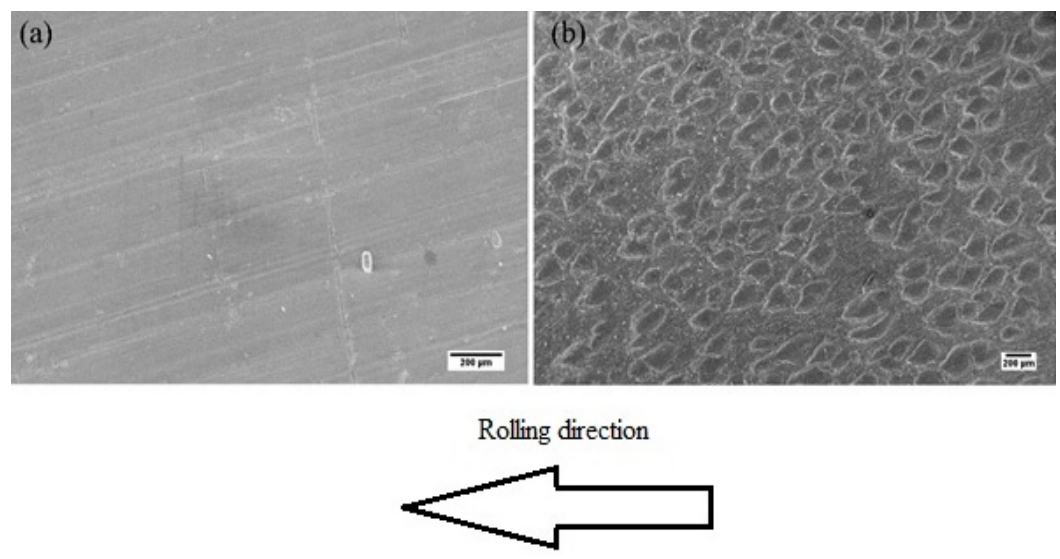

Figure 1. The surface of aluminum strips (a) before wire brushing and (b) after wire brushing.

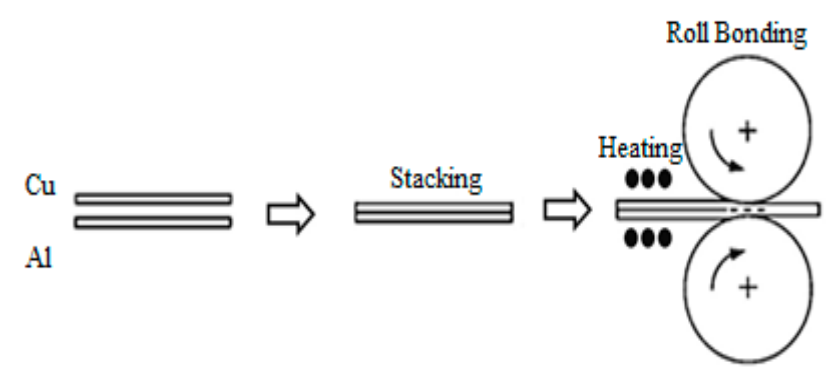

Figure 2. Schematic diagram of the Roll Bonding (RB) process.

To set up the RB process, a rolling machine with a 100-mm roll diameter, $36 \mathrm{rpm}$ of rotational speed, and a power capacity of $35 \mathrm{hp}$ was used. The tensile test specimens were machined from the rolled strips according to the ASTM E8M standard which were oriented along the rolling direction, as shown in Figure 3 [20]. The gage length and the width of tensile test specimens were 25 and $6 \mathrm{~mm}$, respectively. Tensile tests were conducted at ambient temperature on a H50KS testing machine at a strain rate of $1.67 \times 10^{-4} \mathrm{~S}^{-1}$. Also, the peeling test was performed using an Instron tensile testing machine with $100 \mathrm{~kg}$ load cell. The mean peeling force was measured by a clamping configuration, as shown in Figure 4 . The speed of the crosshead in the peeling test was $20 \mathrm{~mm} / \mathrm{min}$. The bond strength of $\mathrm{Al}$ and $\mathrm{Cu}$ bimetal laminates was measured using the peeling test according to ASTM-D903-93, and the tensile test was repeated three times for each sample [21]. In the peeling test, the average peeling force was measured as can be shown typically in Figure 4, and the average peel strength was taken as [21]:

$$
\text { Average peel strength }=\frac{\text { Average load }}{\text { Bond width }}
$$

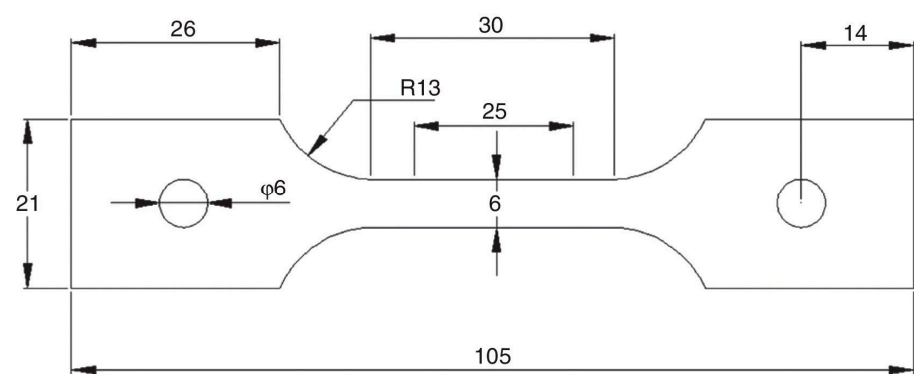

Figure 3. Orientation of the tensile test specimens (ASTM-E8M) [20]. 


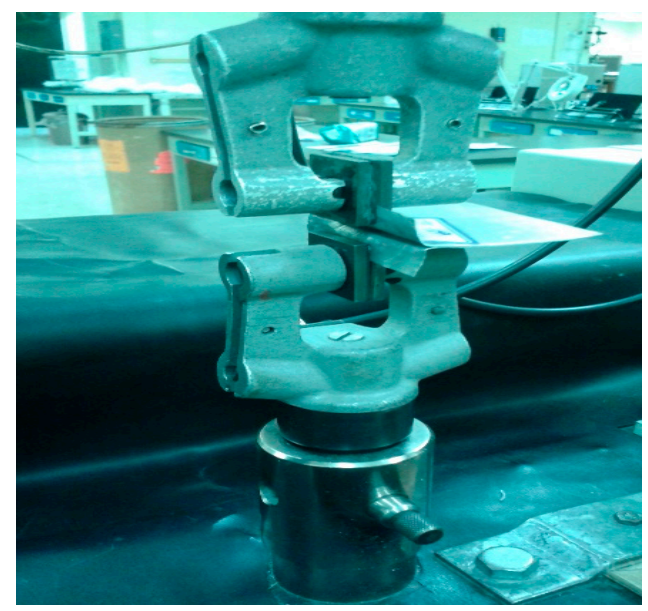

Figure 4. Schematic illustration of the peeling test fixture.

\subsection{Numerical Simulation}

The roll bonding (RB) technique was used to fabricate bimetallic laminates. Figure 2 shows a schematic diagram of the rolling process of $\mathrm{Al} / \mathrm{Cu}$ bimetallic laminates. In Figure 2, the horizontal and vertical directions are the longitudinal and normal directions. In the two-dimensional Finite Element (FE) model of the RB process set up in ABAQUS software, the initial thickness of both layers ( $\mathrm{Al}$ and $\mathrm{Cu}$ ) was $1 \mathrm{~mm}$. Dynamic Explicit solver is used to solve the process and work rolls. The center of the work rolls were regarded as a center for applying the boundary conditions. In the RB process, the thickness reduction ratios chosen were $10 \%, 20 \%$, and $30 \%$ at $100{ }^{\circ} \mathrm{C}, 200{ }^{\circ} \mathrm{C}$, and $300{ }^{\circ} \mathrm{C}$, respectively, with different forward and backward tensile stresses being exerted at the end of the strips. During the rolling process, the plastic deformation was regarded as plane strain condition and the rolls were regarded as rigid. The isotropic material model was used for modeling $\mathrm{Al}$ and $\mathrm{Cu}$ layers. During the rolling process, temperature change and sheet width spread were neglected. The geometric models were meshed with square elements and, after conducting the mesh senility analysis, the model contained 1100 elements. The FE meshing of bimetallic strips for the roll bonding process is shown in Figure 5. The rolls rotated with a constant angular velocity of $5 \mathrm{rad} / \mathrm{s}$ in the rolling process. Then, the $\mathrm{Al} / \mathrm{Cu}$ strips entered the gap between the rolls with an initial velocity and exited under the action of frictional forces. The physical and mechanical properties of the $\mathrm{Cu}$ and $\mathrm{Al}$ strips used in this study are presented in Table 1. As illustrated in Figure 5, the work rolls were regarded as rigid materials and the strips were meshed with CPE4R meshes [21].

Table 1. Physical and mechanical properties of $\mathrm{Cu}$ and $\mathrm{Al}$ strips.

\begin{tabular}{cccc}
\hline Elastic Modulus (GPa) & Poisons Ratio & Density $\left(\mathbf{K g} / \mathbf{m}^{\mathbf{3}}\right)$ & Strip \\
\hline 110 & 0.3 & 8900 & $\mathrm{Cu}$ \\
70 & 0.3 & 2700 & $\mathrm{Al}$ \\
\hline
\end{tabular}




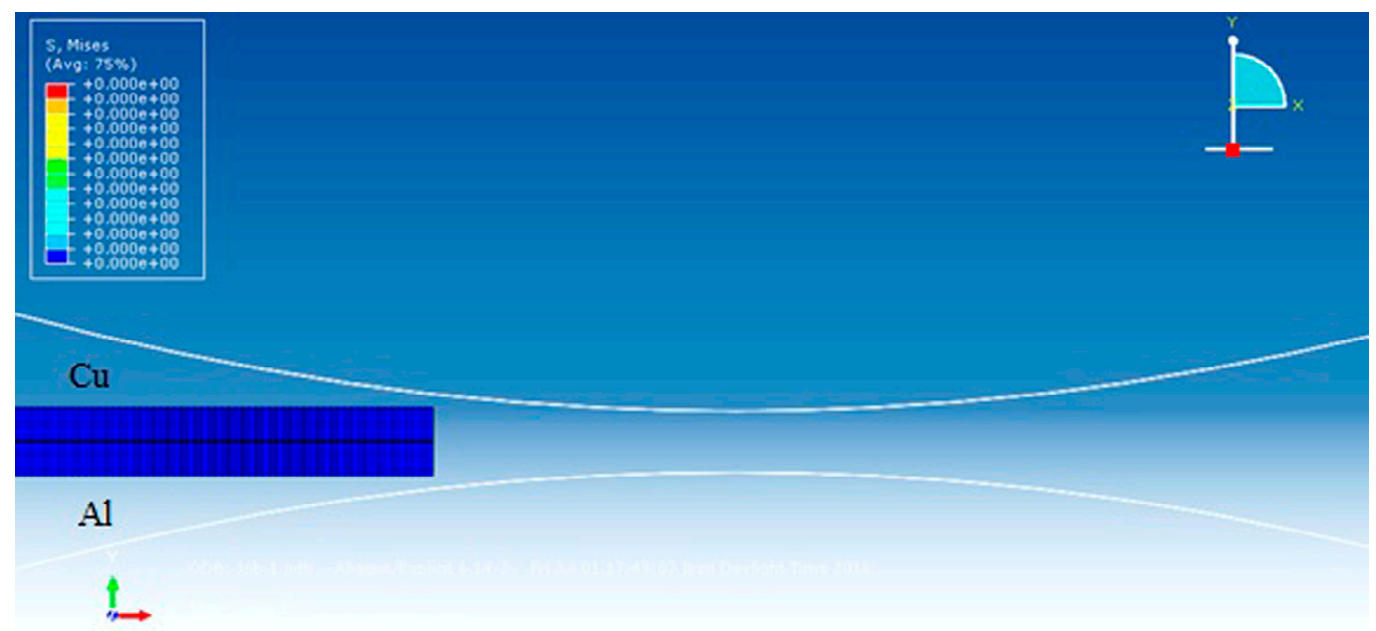

Figure 5. Geometry and Finite Element (FE) meshing of the bimetallic strip rolling.

\section{Results and Discussions}

\subsection{FE Simulation Results}

Figure 6 shows the rolling process of bimetal $\mathrm{Al} / \mathrm{Cu}$ laminates. According to Figure 6, due to the difference of the yield stress of $\mathrm{Al}$ and $\mathrm{Cu}$ strips, the rolling process is not symmetrical along the thickness of strips due to the longitudinal direction. So, there is an asymmetrical stress distribution along the thickness length.

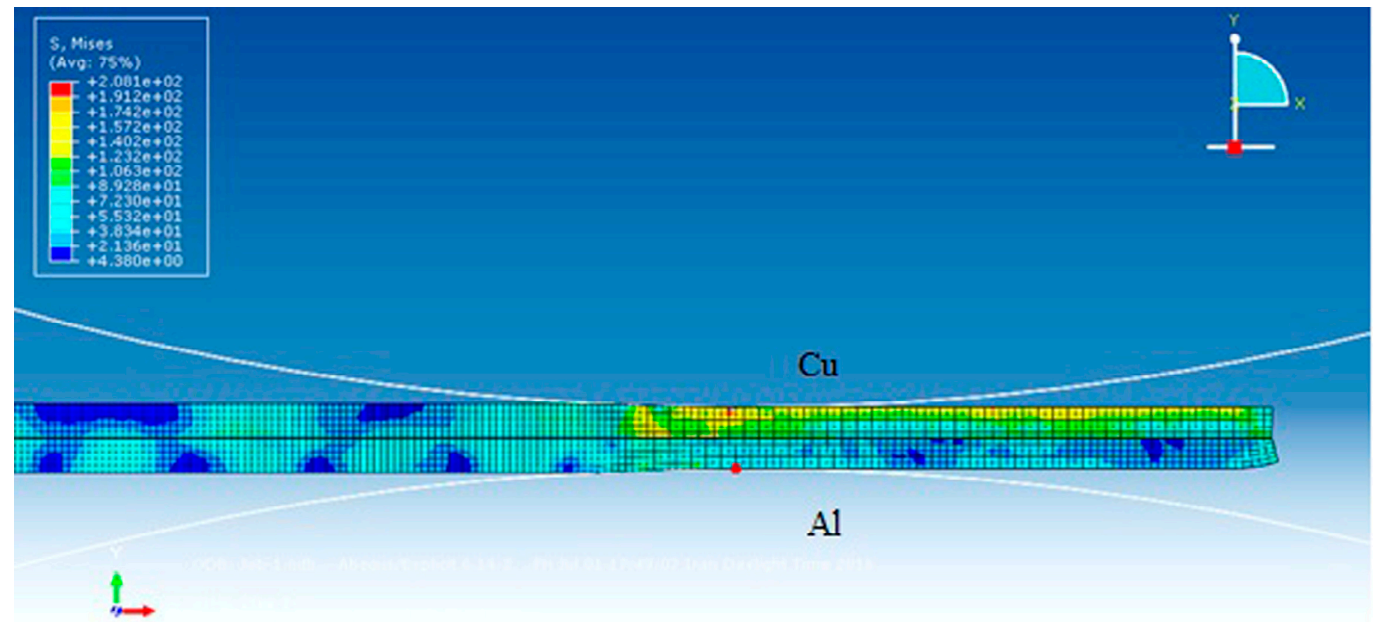

Figure 6. Rolling process of bimetal $\mathrm{Al} / \mathrm{Cu}$ laminates.

Figure 7 shows the maximum stress for the rolling process of bimetal $\mathrm{Al} / \mathrm{Cu}$ laminates with $30 \%$ reduction ratio and with 80,90 , and $100 \mathrm{~mm}$ of roll diameter at different rolling temperatures. According to Figures 7 and 8, by increasing the work roll diameter, the forming stress increases slightly. According to Figure 7, increasing the roll diameter leads to increasing the shear stress along the rolling length, which improves the normal rolling pressure. Also, Figure 7 shows that increasing the rolling temperature decreases the rolling pressure considerably because, in this state, the forming strength of the strips decreases drastically. 


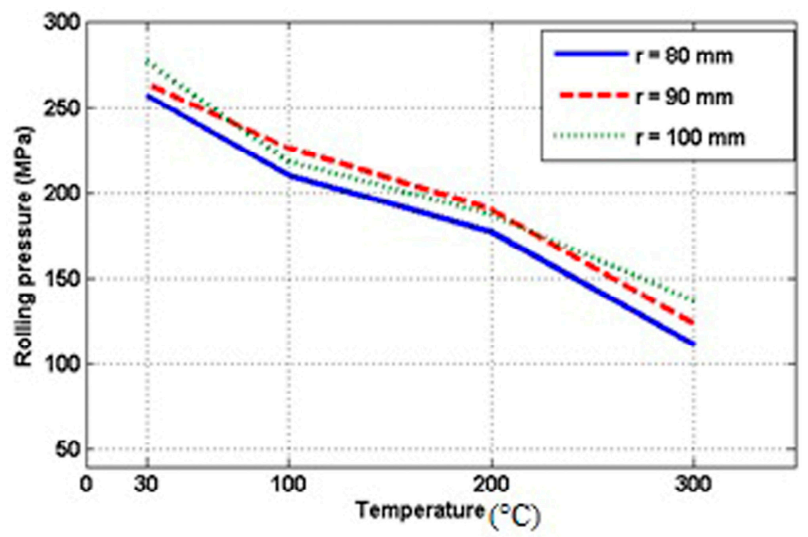

Figure 7. Maximum stress exerted on the bimetal strips with $30 \%$ of thickness reduction ratio at different roll diameters and rolling temperatures.

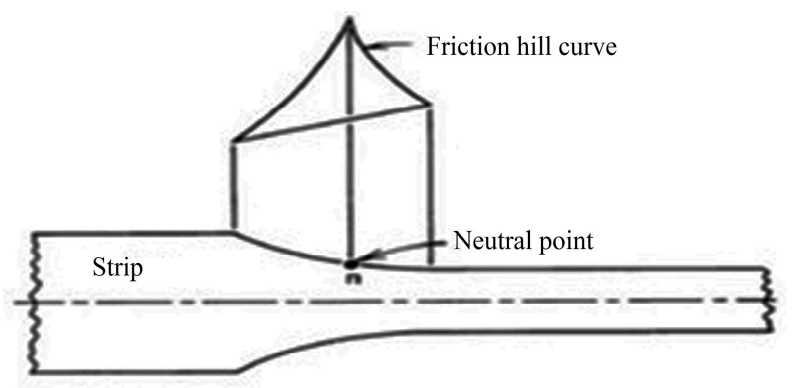

Figure 8. Compression of a strip between two work rolls [21].

According to Figures 9 and 10, increasing the rolling thickness reduction ratio leads to increasing the maximum rolling pressure, which is a clear basic in forming processes. As can be seen in Figure 7, Figure 9, and Figure 10, the rolling stress increases with increasing the thickness reduction ratio up to $20 \%$ and $30 \%$. Most of the shear stress is in the interface of the rolls and the aluminum and copper strips. Table 2 shows the effect of the average of forward and backward tensile stresses on the rolling pressure for the sample rolled at $100{ }^{\circ} \mathrm{C}$ with $20 \%$ of total thickness reduction ratio. According to Table 2, increasing the tensile stress decreases the rolling pressure considerably. This decreasing amount increases again upon increasing the total thickness reduction ratio.

Table 2. Variations of the rolling force versus the average tensile stress.

\begin{tabular}{cccc}
\hline $20 \%$ & $10 \%$ & 0 & Reduction in thickness \\
\hline 0.9 & 0.95 & 1 & $\frac{\text { Average tensile stress }}{\text { Forming strength of the strip }}$ \\
\hline
\end{tabular}




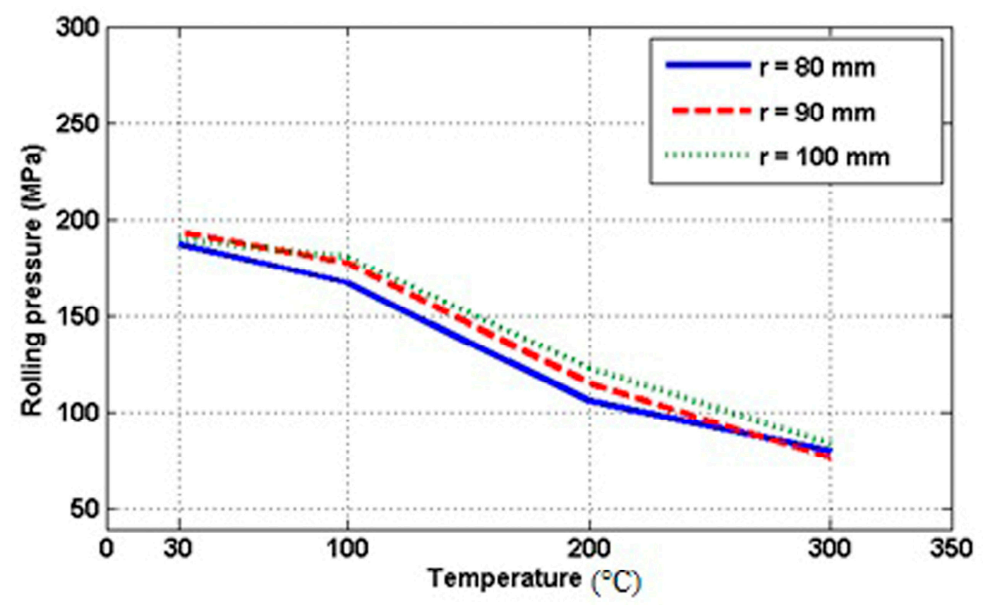

Figure 9. Maximum stress exerted on the bimetal strips with $20 \%$ of thickness reduction ratio at different roll diameters and rolling temperatures.

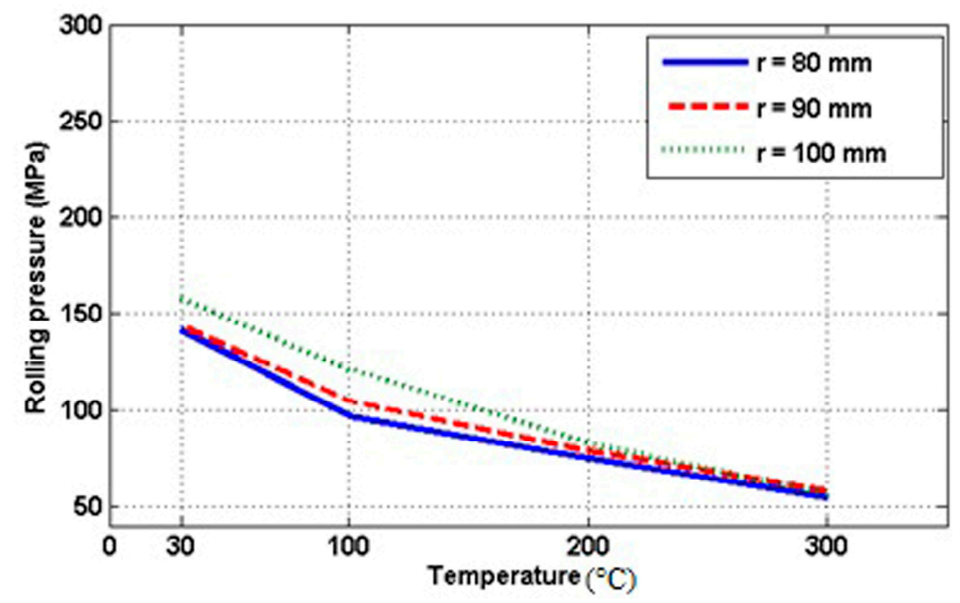

Figure 10. Maximum stress exerted on the bimetal strips with $10 \%$ of thickness reduction ratio at different roll diameters and rolling temperatures.

\subsection{Bonding Strength}

Figure 11 shows the bonding strength of samples versus different thickness reduction ratios at $300^{\circ} \mathrm{C}$. As can be seen in Figure 11, the bond strength increases rapidly with the plastic deformation. According to Figure 7, Figure 8, and Figure 10, FE simulation shows that by increasing the thickness reduction ratio, the rolling pressure increases. According to Figure 11, the average peeling force increases from $12 \mathrm{~N}$ to $28 \mathrm{~N}$ and $40 \mathrm{~N}$ for the samples produced with $10 \%, 20 \%$, and $30 \%$ of thickness reduction ratio, registering $133.3 \%$ and $233.3 \%$ improvements, respectively. So, increasing the rolling pressure leads to the enhancement of shear deformation, surface expansion, size of cracks, and extrusion of the virgin metal during the bonding process. The amount of underlying virgin metal under a high amount of rolling pressure provides a strong mechanical bonding. Also, the generated heat of deformation promotes the atom diffusion in the interfacial zone during the warm working to obtain the metallurgical bonding. The clad sheet with strong interfacial bonding keeps a good interface and deforms uniformly in the tension test. However, there are some micro cracks at the interfaces of samples with weak interfacial bonding, which become destroyed from these positions firstly. So, the laminates fabricated with higher thickness reduction ratios have better interface bonding. 


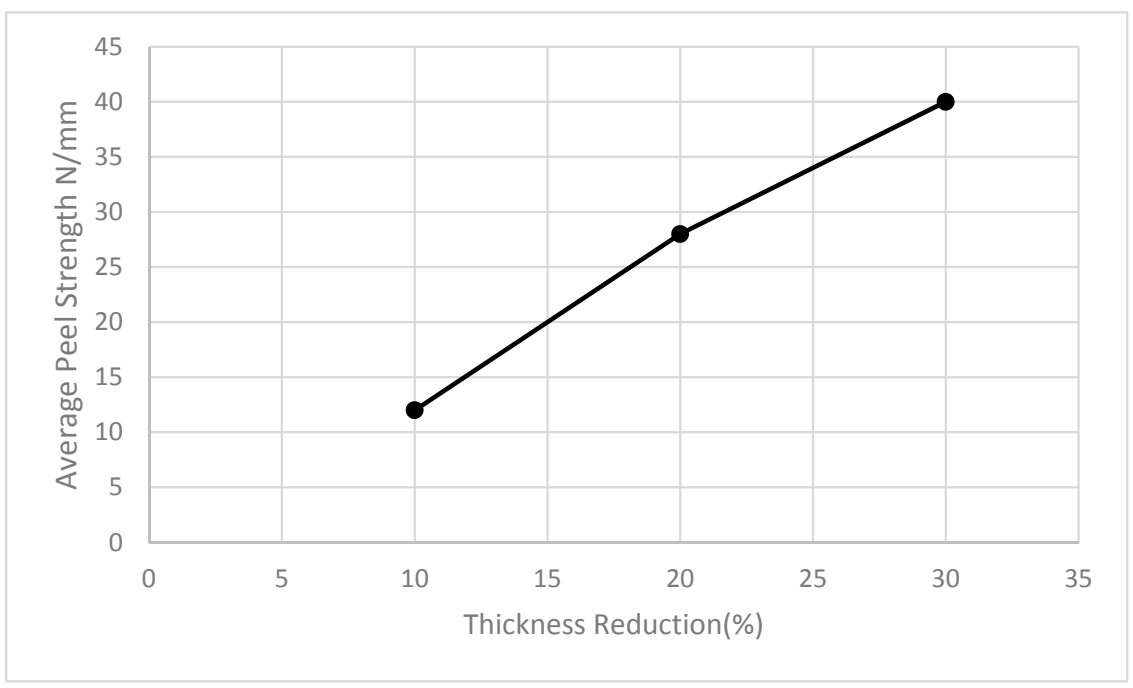

Figure 11. Variation of the average peeling force of $\mathrm{Al} / \mathrm{Cu}$ bimetallic laminates versus total thickness reduction ratios at $300^{\circ} \mathrm{C}$.

\subsection{Bonding Interface}

Figure 12 shows the feature of fracture surfaces at the interface between $\mathrm{Al} / \mathrm{Cu}$ layers after the tensile test. Figure 12a shows the fracture surface of the sample produced with $10 \%$ of thickness reduction. According to Figure 12a, the interface between $\mathrm{Al} / \mathrm{Cu}$ layers has some splits in the tensile process. After roll bonding with a thickness reduction of $30 \%$, the bond quality improves greatly and the interface between $\mathrm{Al}$ and $\mathrm{Cu}$ layers shows decreasing splits (Figure 12b). As can be seen from Figure 12b, it is difficult to identify the interface of the two components in the micrograph. In other words, by increasing the thickness reduction ratio, aluminum and copper matrices have a better flow among their interface and, as a result, the roll bonding improves.
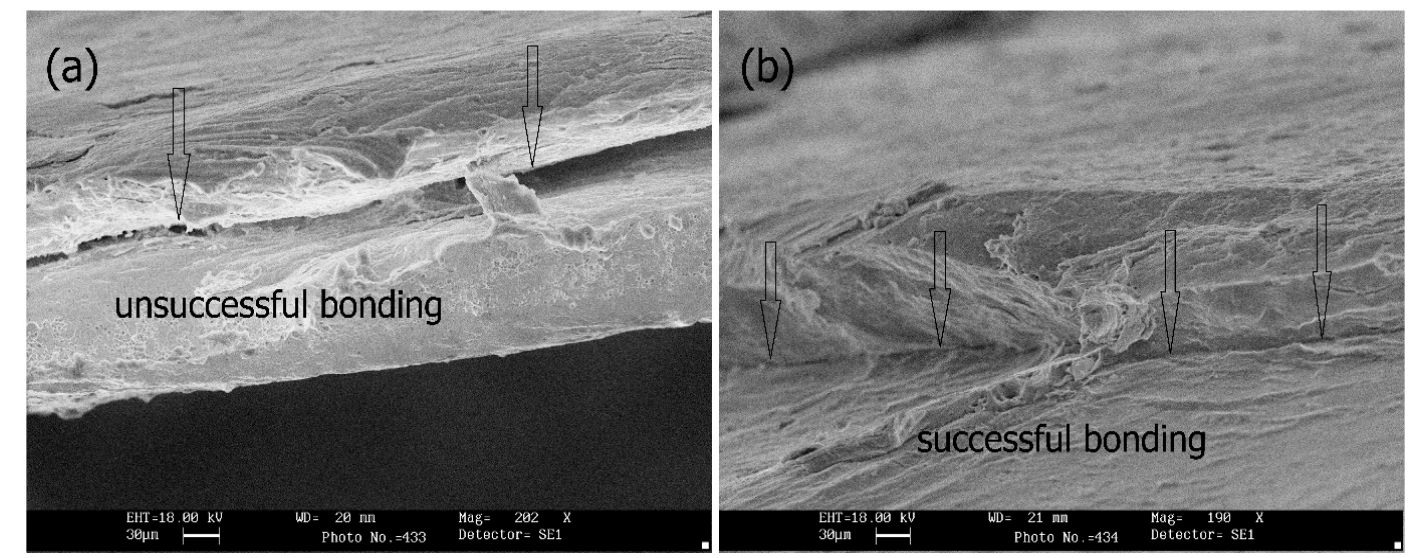

Figure 12. SEM images of the fracture surface around the interface of $\mathrm{Al} / \mathrm{Cu}$ layers after the tensile test with (a) $10 \%$, and (b) $30 \%$ of thickness reduction.

\section{Conclusions}

In this study, the experimental investigation and finite element simulation of the roll bonding process of bimetal $\mathrm{Al} / \mathrm{Cu}$ laminates in ABAQUS software were successfully conducted. The following points can be concluded: 
1. Backward and forward tensile stresses being exerted at the end of the strip decrease the rolling pressure at the rolling bite.

2. By increasing the roll diameter, the shear stresses due to frictional forces between the work rolls and strips along the rolling length increase, which leads to the enhancement of the rolling pressure.

3. Increasing the rolling temperature severely decreases the forming strength of the strips and decreases the rolling pressure.

4. The bimetal $\mathrm{Al} / \mathrm{Cu}$ rolling process is an asymmetrical process with asymmetrical stress distribution along the thickness of the strips. This asymmetric distribution affects the final geometry of the rolled product.

5. The bond strength of $\mathrm{Al} / \mathrm{Cu}$ samples improves by increasing the total thickness reduction ratio from $12 \mathrm{~N}$ up to $28 \mathrm{~N}$ and $40 \mathrm{~N}$ for samples produced with $10 \%, 20 \%$, and $30 \%$ of thickness reduction ratio, respectively [21]. By increasing the total thickness reduction ratio, the plastic shear stress at the interface increases, which leads to an increase in the rolling pressure and bonding quality.

6. SEM images show that the bond strength of $\mathrm{Al} / \mathrm{Cu}$ laminates improves with increasing the total thickness reduction ratio from $10 \%$ up to $30 \%$, registering a $233.3 \%$ improvement [21]. So, by increasing the plastic shear stress at the interface due to high reduction in thickness, the rolling pressure and, as a result, the bonding quality improves.

Acknowledgments: The authors gratefully acknowledge the manufacturing technology research center of the Islamic Azad University, Majlesi branch, for the provision of experimental set up and research facilities used in this work

Author Contributions: Mohammad Heydari Vini and Saeed Daneshmand conceived and designed the experiments; Saeed Daneshmand and Mostafa Forooghi performed the experiments; Mohammad Heydari Vini analyzed the data; all authors contributed to the writing of the paper. All authors have read and approved the final manuscript.

Conflicts of Interest: The authors declare no conflict of interest.

\section{References}

1. Chang, H.; Zheng, M.Y.; Gan, W.M.; Wu, K.; Maawad, K.; Brokmeier, H.G. Texture evolution of the Mg/Al laminated composite fabricated by roll bonding. Scr. Mater. 2009, 61, 717-720. [CrossRef]

2. Chen, M.C.; Hsieh, H.C.; Wu, W. The evolution of microstructures and mechanical properties during accumulative roll bonding of $\mathrm{Al} / \mathrm{Mg}$ composite. J. Alloys Compd. 2006, 416, 169-172. [CrossRef]

3. Wu, K.; Chang, H.; Maawad, E.; Gan, W.M.; Brokmeier, H.G.; Zheng, M.Y. Microstructure and mechanical properties of the $\mathrm{Mg} / \mathrm{Al}$ laminated composite fabricated by accumulative roll bonding (ARB). Mater. Sci. Eng. A 2009, 527, 3073-3078. [CrossRef]

4. Kavarana, F.H.; Ravichandran, K.S.; Sahay, S.S. Nano scale steel-brass multilayer laminates made by cold rolling: microstructure and tensile properties. Scr. Mater. 2000, 42, 947-954. [CrossRef]

5. Ohsaki, S.; Kato, S.; Tsuji, N.; Ohkubo, T.; Hono, K. Effect of Zn additions on the age-hardening of Mg-2.0 Gd-1.2 Y-0.2 Zr alloys. Acta Mater. 2007, 55, 2885-2895. [CrossRef]

6. Haghiri, A.; Ketabchi, M.; Parvin, N. The Effect of Annealing Temperature on the Bond Strength and Structure of Interface in Ag/Cu Strips. J. Fac. Eng. 2008, 41, 1095-1101.

7. Dehsorkhi, R.N.; Qods, F.; Tajally, M. Investigation on microstructure and mechanical properties of Al-Zn composite during accumulative roll bonding (ARB) process. Mater. Sci. Eng. A 2011, 530, 63-72. [CrossRef]

8. Mozaffari, A.; Danesh Manesh, H.; Janghorban, K. Evaluation of mechanical properties and structure of multilayered $\mathrm{Al} / \mathrm{Ni}$ composites produced by accumulative roll bonding (ARB) process. J. Alloys Compd. 2011, 489, 103-109. [CrossRef]

9. Tang, C.; Liu, Z.; Zhou, A.D.; Wu, S. Surface treatment with the cold roll bonding process for an aluminum alloy and mild steel. Strength Mater. 2015, 47, 150-155. [CrossRef]

10. Wei, K.X.; Wei, W.; Du, Q.B.; Hu, J. Microstructure and tensile properties of Al-Mn alloy processed by accumulative roll bonding. Mater. Sci. Eng. A 2009, 525, 55-59. [CrossRef] 
11. Eizadjou, M.; Manesh, H.D.; Janghorban, K. Microstructure and mechanical properties of ultra-fine grains (UFGs) aluminum strips produced by ARB process. J. Alloys Comp. 2009, 474, 406-415. [CrossRef]

12. Alvandi, H.; Farmanesh, K. Microstructural and mechanical properties of nano/ultra-fine structured 7075 aluminum alloy by accumulative roll-bonding process. Procedia Mater. Sci. 2015, 11, 17-23. [CrossRef]

13. Mehr, V.Y.; Toroghinejad, M.R.; Rezaeian, A. The effects of oxide film and annealing treatment on the bond strength of Al-Cu strips in cold roll bonding process. Mater. Des. 2014, 53, 174-181. [CrossRef]

14. Abbasi, M.; Toroghinejad, M.R. Effects of processing parameters on the bond strength of $\mathrm{Cu} / \mathrm{Cu}$ roll-bonded strips. J. Mater. Process. Technol. 2010, 210, 560-563. [CrossRef]

15. Li, L.; Nagai, K.; Yin, F. Progress in cold roll bonding of metals. Sci. Technol. Adv. Mater. 2008, 9, 023001. [CrossRef] [PubMed]

16. Dixit, U.S.; Dixit, P.M. A finite element analysis of flat rolling and application of fuzzy set theory. Int. Mach. Tools Manuf. 1996, 36, 947-952. [CrossRef]

17. Shi, J.; McElwain, D.L.S.; Langlands, T.A.M. A comparison of methods to estimate the roll torque in thin strip rolling. Int. J. Mech. Sci. 2001, 43, 611-630. [CrossRef]

18. Schey, J.A. Tribology in Metalworking: Friction, Lubrication and Wear; ASM International: Russell Township, OH, USA, 1983; pp. 27-130.

19. Inoue, T.; Yanagida, A.; Yanagimoto, J. Finite element simulation of accumulative roll-bonding process. Mater. Lett. 2013, 106, 37-40. [CrossRef]

20. ASTM. E8/E8M Standard Test Methods for Tension Testing of Metallic Materials 1; ASTIM International: West Conshohocken, PA, USA, 2010; pp. 1-27.

21. Vini, M.H.; Sedighi, M.; Mondali, M. Investigation of Bonding Behavior of AA1050/AA5083 Bimetallic Laminates by Roll Bonding Technique. Trans. Indian Inst. Met. 2017. [CrossRef]

(C) 2017 by the authors. Licensee MDPI, Basel, Switzerland. This article is an open access article distributed under the terms and conditions of the Creative Commons Attribution (CC BY) license (http:/ / creativecommons.org/licenses/by/4.0/). 